OPEN ACCESS

Edited by:

Frank Ebel,

Ludwig Maximilian University

of Munich, Germany

Reviewed by:

Sven Krappmann

University of Erlangen-Nuremberg,

Germany

Anurag Singh,

Tübingen University Hospital,

Germany

*Correspondence:

Josiane S. Neves

jneves@icb.ufri.br

†These authors have contributed equally to this work

Specialty section

This article was submitted to

Infectious Diseases,

a section of the journal

Frontiers in Microbiology

Received: 25 November 2020

Accepted: 27 January 2021

Published: 18 February 2021

Citation:

Barroso MV, Gropillo I, Detoni MAA, Thompson-Souza GA,

Muniz VS, Vasconcelos CRl,

Figueiredo RT, Melo RCN and

Neves JS (2021) Structural

and Signaling Events Driving Aspergillus fumigatus-Induced Human Eosinophil Extracellular Trap Release.

Front. Microbiol. 12:633696.

doi: 10.3389/fmicb.2021.633696

\section{Structural and Signaling Events Driving Aspergillus fumigatus-Induced Human Eosinophil Extracellular Trap Release}

\author{
Marina Valente Barroso ${ }^{1,2 t}$, Isabella Gropillo ${ }^{1 t}$, Marcella A. A. Detoni', \\ Glaucia A. Thompson-Souza², Valdirene S. Muniz², Claudia Regina Isaías Vasconcelos², \\ Rodrigo T. Figueiredo ${ }^{3}$, Rossana C. N. Melo ${ }^{4}$ and Josiane S. Neves ${ }^{2 *}$
}

\footnotetext{
'Institute of Microbiology Paulo de Góes, Federal University of Rio de Janeiro, Rio de Janeiro, Brazil, ${ }^{2}$ Institute of Biomedical Sciences, Federal University of Rio de Janeiro, Rio de Janeiro, Brazil, ${ }^{3}$ Institute of Biomedical Sciences/Campus of Duque de Caxias, Federal University of Rio de Janeiro, Rio de Janeiro, Brazil, ${ }^{4}$ Laboratory of Cellular Biology, Department of Biology, Institute of Biological Sciences, Federal University of Juiz de Fora, Juiz de Fora, Brazil
}

Eosinophils are granulocytes classically involved in allergic diseases and in the host immune responses to helminths, fungi, bacteria and viruses. The release of extracellular DNA traps by leukocytes is an important mechanism of the innate immune response to pathogens in various infectious conditions, including fungal infections. Aspergillus fumigatus is an opportunistic fungus responsible for allergic bronchopulmonary aspergillosis (ABPA), a pulmonary disease marked by prominent eosinophilic inflammation. Previously, we demonstrated that isolated human eosinophils release extracellular DNA traps (eosinophil extracellular traps; EETs) when stimulated by A. fumigatus in vitro. This release occurs through a lytic non-oxidative mechanism that involves CD11b and Syk tyrosine kinase. In this work, we unraveled different intracellular mechanisms that drive the release of extracellular DNA traps by $A$. fumigatus-stimulated eosinophils. Ultrastructurally, we originally observed that $A$. fumigatus-stimulated eosinophils present typical signs of extracellular DNA trap cell death (ETosis) with the nuclei losing both their shape (delobulation) and the euchromatin/heterochromatin distinction, followed by rupture of the nuclear envelope and EETs release. We also found that by targeting class I PI3K, and more specifically PI3K $\delta$, the release of extracellular DNA traps induced by $A$. fumigatus is inhibited. We also demonstrated that $A$. fumigatus-induced EETs release depends on the Src family, Akt, calcium and p38 MAPK signaling pathways in a process in which fungal viability is dispensable. Interestingly, we showed that $A$. fumigatus-induced EETs release occurs in a mechanism independent of PAD4 histone citrullination. These findings may contribute to a better understanding of the mechanisms that underlie EETs release in response to A. fumigatus, which may lead to better knowledge of ABPA pathophysiology and treatment.

\footnotetext{
Keywords: eosinophils, A. fumigatus, extracellular DNA traps, allergic bronchopulmonary aspergillosis, ABPA
} 


\section{INTRODUCTION}

Eosinophils are bone marrow-derived granulocytes that are typically abundant in inflammatory infiltrates in the defense against helminthic parasites and in allergic diseases. However, various immunoregulatory actions and functions have been also described for eosinophils, such as lymphocyte recruitment, tissue repair, organ development, antigen presentation, antimicrobial and antifungal activities, among other functions (Strandmark et al., 2016). Two of the main eosinophil activation mechanisms are degranulation and, more rarely, phagocytosis (Shamri et al., 2011). Recently, another cell effector mechanism has been described for eosinophils-the release of extracellular DNA traps (Yousefi et al., 2008; Ueki et al., 2013). The release of extracellular DNA traps (ETs) by leukocytes has been considered an important mechanism of the immune response in different inflammatory conditions. Although most ET knowledge is based on neutrophil studies (Brinkmann et al., 2004; Fuchs et al., 2007; Parker et al., 2012), it is well known that other leukocytes are also able to release ETs, including eosinophils (Yousefi et al., 2008), mast cells (von Kockritz-Blickwede et al., 2008), monocytes/macrophages (Chow et al., 2010), dendritic cells (Ramirez-Ortiz et al., 2011; Loures et al., 2015) and basophils (Schorn et al., 2012; Morshed et al., 2014). Various stimuli are capable of inducing the release of ETs, which essentially are structures of disrupted chromatin filaments coated with granular and cytosolic proteins, histones, and proteases (Brinkmann et al., 2004; Fuchs et al., 2007; Guimaraes-Costa et al., 2009; Parker et al., 2012). ET release involves non-lytic (Yousefi et al., 2008, 2009; Yipp et al., 2012) or lytic processes (named ETosis) that in general require cell chromatin decondensation (Brinkmann et al., 2004; Fuchs et al., 2007; Guimaraes-Costa et al., 2009; Parker et al., 2012; Ueki et al., 2013). Some studies indicate that this process is due to histone hypercitrullination by the enzyme PAD4 (peptidylarginine deiminase 4), in which arginine residues in histones are converted to citrulline, allowing DNA fibers to unfold (Wang et al., 2009; Li et al., 2010; Lewis et al., 2015; Van Avondt and Hartl, 2018). However, controversy remains about the relative importance of PAD4 for ETs release (Neeli and Radic, 2013; Kenny et al., 2017; Claushuis et al., 2018; Guiducci et al., 2018; Silva et al., 2019; Thompson-Souza et al., 2020). Interestingly, some studies have indicated that mitochondria are the source of the DNA that composes ETs (Yousefi et al., 2008, 2009). ETs help leukocytes immobilize bacteria, fungi and viruses, creating a microenvironment that favors a more efficient elimination of pathogens (Brinkmann et al., 2004; Fuchs et al., 2007; Papayannopoulos et al., 2010; Parker et al., 2012). However, recent evidence has emerged suggesting that ETs also have a role in non-infectious sterile inflammation (Jorch and Kubes, 2017). In eosinophils, the process by which they produce and release eosinophil extracellular DNA traps (EETs) can result in cell death (named EETosis in eosinophils) (Ueki et al., 2013); or in a nonlytic process by which eosinophils rapidly produce EETs but do not lose their viability (Yousefi et al., 2008, 2009).

Exposure and sensitization to fungal allergens is an important factor in patients with respiratory allergies; in this context, fungi play an important role in the development, severity and persistence of allergic lung diseases (Knutsen et al., 2012; Denning et al., 2014). Allergic bronchopulmonary mycoses (ABPMs) are characterized by fungal colonization and are known to worsen lung function, which is commonly associated with the development of severe asthma (Denning et al., 2013, 2014; Chowdhary et al., 2014). Aspergillus fumigatus is the most common cause of ABPMs; to a lesser extent, C. albicans and Alternaria species are also related to the development of these diseases (Shah and Panjabi, 2002; Chowdhary et al., 2014). ABPA, a form of non-invasive eosinophilic pulmonary aspergillosis, is a multifaceted pulmonary disorder caused by immunological reactions in response to repeated antigen exposure and/or colonization by A. fumigatus (Agarwal et al., 2013; Ueki et al., 2018). Susceptibility is related to the pathophysiology of comorbidities such as asthma, sinusitis, cystic fibrosis and alveolitis (Kousha et al., 2011; Denning et al., 2014). We recently described the presence of EETs in sputum samples from ABPA patients and found that human eosinophils are capable of releasing EETs in vitro in response to A. fumigatus conidia in a lytic non-oxidative process that involves CD11b and the Syk signaling pathway (Muniz et al., 2018). However, the ultrastructural features and signaling events that characterize and drive A. fumigatus-induced EETosis in human eosinophils are not completely understood. Thus, the purpose of this study was to unravel the intracellular mechanisms that direct the process of extracellular DNA trap release by A. fumigatusstimulated eosinophils.

\section{METHODOLOGY}

\section{Study Approval}

All protocols and experimental procedures that involved human blood-isolated eosinophils were approved by the Committee on Human Research at Clementino Fraga Filho Hospital (Federal University of Rio de Janeiro). Written informed consent was obtained under institutional review board approved protocols (license number CAAE 31968020.9.0000.5257).

\section{Fungal Culture and Conidial Preparation}

A. fumigatus conidia ATCC 46645 (strain NCPF 2109) cryopreserved in liquid nitrogen and maintained in medium that contained $0.9 \%$ saline, $0.01 \%$ Tween, and $30 \%$ glycerol was thawed and spread onto solid potato dextrose agar medium (Neogen, MI, United States). The culture was incubated for $5-7$ days at $37^{\circ} \mathrm{C}$. Plates that contained mycelium of $A$. fumigatus were scraped with sterile PBS containing $0.05 \%$ Tween-20 (Bio-Rad, CA, United States), and the conidia were collected via filtration through a sterile nylon mesh with a porosity of $40 \mu \mathrm{m}$ (BD Biosciences, NJ, United States). The conidia were pelleted by centrifugation $\left(3150 \mathrm{~g}, 25^{\circ} \mathrm{C}, 15 \mathrm{~min}\right)$, resuspended in RPMI 1640 (phenol red-free) (Sigma, MO, United States), and counted using a Neubauer chamber and an optical microscope (Leica Microsystems, Wetzlar, Germany) at $40 \times$ magnification. The cell concentration was adjusted for the subsequent stimulation experiments. For a specific set of experiments, A. fumigatus conidia were fixed in $4 \%$ paraformaldehyde (PFO) for $30 \mathrm{~min}$ 
at room temperature, extensively washed with PBS $(2 \mathrm{ml}$, three times), centrifuged ( $3160 \mathrm{~g}, 15 \mathrm{~min}$ ) and resuspended in RPMI.

\section{Eosinophil Purification}

Eosinophils were isolated from the blood of healthy donors using negative selection as previously described (Muniz et al., 2018). The viability and purity of the freshly isolated eosinophils were more than $99 \%$, as analyzed by trypan blue exclusion and panoptic kit staining, respectively.

\section{Fluorimetric Assay for EET Quantification}

Purified human eosinophils $\left(2 \times 10^{5} / 200 \mu \mathrm{L}\right)$ were resuspended in RPMI 1640 (phenol red-free) supplemented with $0.1 \%$ heat-inactivated fetal calf serum (Life Technologies, CA, United States), 1\% L-glutamine (Life Technologies) and antibiotics (penicillin and streptomycin). The eosinophils were stimulated in 96-well tissue culture plates with A. fumigatus conidia at a cell:fungus ratio of $1: 10$ for $6 \mathrm{~h}$ at $37^{\circ} \mathrm{C}$, conditions that were previously determined in previous studies (Muniz et al., 2018). Ten minutes before the end of the incubation time, Sytox Green ( $5 \mu \mathrm{M}$, Life Technologies), an extracellular DNA probe impermeable to viable cells, was added to the wells. The samples were analyzed in a FlexStation plate reader (Molecular Devices, CA, United States) with a wavelength combination of excitation at $485 \mathrm{~nm}$ and emission at $538 \mathrm{~nm}$. The values are expressed in relative fluorescence units. To evaluate the participation of different signaling pathways in A. fumigatusinduced release of EETs, the eosinophils were pretreated for 30 min before fungal stimulation with the following inhibitors: PP2 (10 $\mu \mathrm{M}$, Caymann, MI, United States), a pharmacological inhibitor for Src kinases; wortmannin (100 $\eta \mathrm{M}$, Sigma), a PI3K pan-inhibitor; Akt inhibitor VIII (2.6 $\mu \mathrm{M}$, Cayman), an Akt inhibitor; SB202190 (10 $\mu$ M, Calbiochem, CA, United States), a p38 MAPK inhibitor; AS605240 (Cayman), at $10 \mu \mathrm{M}$, a selective inhibitor of the class I PI3K family; IC-87114 (Cayman), at $1 \mu \mathrm{M}$, a selective PI3K $\delta$ inhibitor; GSK484 (10 $\mu \mathrm{M}$, GlaxoSmithKline, Brentford, United Kingdom), a PAD4 inhibitor; and BAPTA-AM (10 $\mu \mathrm{M}$, Sigma), a calcium chelating agent. In all conditions, the inhibitor vehicle, dimethyl sulfoxide (DMSO), was tested at the corresponding dilution. 0

\section{Confocal Microscopy}

Purified human eosinophils $\left(2 \times 10^{5} / 1000 \mu \mathrm{L}\right)$ were placed in a 24-well plate that contained coverslips pretreated with poly-L-lysine $(0.001 \%)$ (Sigma). Before fungal stimulation, the eosinophils were pretreated for $30 \mathrm{~min}$ with the pharmacological inhibitors described above. The cells were subsequently stimulated with $A$. fumigatus conidia at a cell: fungus ratio of 1:10 and were maintained at $37^{\circ} \mathrm{C}$ with $5 \% \mathrm{CO}_{2}$ for $6 \mathrm{~h}$. At the end of the incubation time, the culture medium was removed, and the adhered cells were fixed with $4 \%$ PFO for $15 \mathrm{~min}$ at room temperature (RT). The cells were washed three times with sterile PBS. Sytox Green (5 $\mu \mathrm{M})$ or Hoechst (1:1000, Life Technologies) was subsequently added and incubated for $10 \mathrm{~min}$ for DNA labeling. For histone labeling, the samples were fixed with $4 \%$
PFO and permeabilized with PBS buffer containing 1\% Triton X-100 and 2\% NP40. They were then labeled with a mouse anti-human citrullinated histone $\mathrm{H} 3$ antibody $(0.8 \mu \mathrm{g} / \mathrm{mL}$, Abcam, Cambridge, United Kingdom) diluted in PBS containing $0.05 \%$ Tween-20, 2\% BSA, and 5\% human serum. Following an overnight incubation at $4^{\circ} \mathrm{C}$, the cells were washed and incubated for $1 \mathrm{~h}$ with a rabbit anti-mouse IgG fluorescein isothiocyanateconjugated antibody (1:1000, Jackson ImmunoResearch, ME, United States). The wells were then washed 3 times, followed by the addition of the mounting medium Aqua-Poly/Mount. Images were acquired using a fluorescence confocal microscope (Leica TCS SP5, Leica Microsystems, Wetzlar, Germany) and were analyzed with the ImageJ program (Fiji).

\section{Immunoblotting}

Purified human eosinophils $\left(1 \times 10^{6} / 200 \mu \mathrm{L}\right)$ were placed in a 24-well plate and pretreated for $30 \mathrm{~min}$ with the PAD4 inhibitor GSK484 (10 $\mu \mathrm{M}$, GlaxoSmithKline) or its vehicle and then stimulated with A. fumigatus conidia (cell: fungus ratio of 1:10, $37^{\circ} \mathrm{C}, 6 \mathrm{~h}$ ). After incubation, the cells were lysed in sample buffer (Tris $\mathrm{HCl} 62 \mathrm{mM}, 10 \%$ glycerol, 5\% $\beta$-mercaptoethanol, 2\% SDS). The samples were boiled $\left(100^{\circ} \mathrm{C}\right.$ for $\left.5 \mathrm{~min}\right)$, centrifuged to remove insoluble debris, run on a polyacrylamide gel (12\%), and then transferred to a nitrocellulose membrane using a Trans-Blot Semi-Dry Transfer Cell (Bio-Rad). The membranes were blocked with TBS-T (Tris-buffered saline $+0.05 \%$ Tween) containing 5\% BSA and then incubated overnight with a primary rabbit antihuman citrullinated histone $\mathrm{H} 3$ polyclonal antibody $(0.8 \mu \mathrm{g} / \mathrm{mL}$, Abcam) or a rabbit anti-human histone $\mathrm{H} 3$ monoclonal antibody (clone D1H2, Cell Signaling, Massachusetts, United States). The membranes were subsequently incubated for $1 \mathrm{~h}$ with a secondary goat anti-rabbit IgG peroxidase-conjugated antibody (Sigma) and were revealed by chemiluminescence (ECL, Thermo Fisher Scientific, MA, United States).

\section{Transmission Electron Microscopy}

Blood eosinophils were added to chamber slides $\left(2.5 \times 10^{5} /\right.$ chamber $)$, stimulated or not with A. fumigatus conidia (cell: fungus ratio of 1:10) for $6 \mathrm{~h}$, and immediately fixed in a mixture of freshly prepared aldehydes $(2.5 \%$ paraformaldehyde, $2.5 \%$ glutaraldehyde) in $1 \mathrm{M}$ sodium

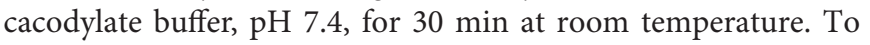
allow optimal cell morphology and observation of extracellular trap formation in situ, all electron microscopy procedures were performed at RT directly on the slide surface as previously described (Ueki et al., 2013). The cells were post-fixed in 1\% osmium tetroxide and processed for transmission electron microscopy (TEM) according to previous studies (Melo et al., 2009). Resin embedding was performed by inverting resin-filled plastic capsules over the slide-attached cells. After polymerization at $60^{\circ} \mathrm{C}$ for $16 \mathrm{~h}$, thin sections were cut using a diamond knife on an ultramicrotome (Leica, Bannockburn, IL, United States). Sections were mounted on uncoated 200-mesh copper grids (Ted Pella, California, United States) before staining with lead citrate and then viewed with a transmission electron microscope (Tecnai G2 Spirit, FEI/Thermo Fisher Scientific) at $80 \mathrm{kV}$. A total 
of 77 randomly acquired electron micrographs were analyzed at different magnifications.

\section{Scanning Electron Microscopy (SEM)}

Purified human eosinophils $\left(2 \times 10^{5} / 200 \mu \mathrm{L}\right)$ were placed in a 24-well plate that contained coverslips pretreated with polyL-lysine $(0.001 \%)$ (Sigma). A. fumigatus conidia were added at a cell: fungus ratio of $1: 10$, and the samples were maintained at $37^{\circ} \mathrm{C}$ with $5 \% \mathrm{CO}_{2}$. After $6 \mathrm{~h}$ of incubation, the culture medium was removed, and cells that adhered to the coverslip were fixed with $2.5 \%$ glutaraldehyde, $4 \%$ formaldehyde $(0.1 \mathrm{M})$ in sodium cacodylate buffer for $2 \mathrm{~h}$ at RT. After three washes in sodium cacodylate buffer $(0.1 \mathrm{~mol} / \mathrm{L})$, the samples were postfixed with $1 \%$ osmium tetroxide and $0.8 \%$ potassium ferrocyanide in sodium cacodylate buffer for $30 \mathrm{~min}$. The samples were again washed three times in sodium cacodylate buffer, followed by dehydration in graded ethanol: $30,50,70,90$, and $100 \%$ for 15 min each. The critical point technique with $\mathrm{CO}_{2}$ was subsequently performed, followed by mounting on a metallic support with carbon tape. The samples were then covered with a thin layer of $20 \mathrm{~nm}$ gold (metallization), followed by examination under a conventional QUANTA 250 FEI scanning electron microscope (ThermoFisher Scientific).

\section{Statistical Analysis}

The results were analyzed with GraphPad Prism 8 using ANOVA with repeated measures and the Newman-Keuls post-test, with statistically significant differences defined as $p<0.05$.

\section{RESULTS}

\section{A. fumigatus-Induced EETosis Is Characterized by Marked Nuclear Alterations}

To investigate the intracellular structural events associated with the formation of EETs by human eosinophils in response to A. fumigatus, cells incubated with this pathogen in chamber slides were fixed and processed for TEM directly on the slide surface, without any additional procedures that could interfere with the cell morphology. This ultrastructural analysis revealed for the first time that eosinophils undergo marked EETosis-associated nuclear alterations upon interaction with A. fumigatus. The typically bilobed nuclei with well-defined euchromatin/heterochromatin areas as seen in control cells (Figure 1A) lost their shape in parallel with chromatin decondensation/expansion, and the distinction between euchromatin/heterochromatin disappeared (Figure 1B). Rupture of the nuclear envelope and plasma membrane (Figure 1C) allowed the release of chromatin-formed EETs (arrowheads in Figure 1Ci) from cytolytic eosinophils and free extracellular granules (FEGs) (Figure 1C). Accordingly, DNAcitrullinated histone EETs released in response to A. fumigatus were consistently immunolabeled (Figures 1D,Di), as previously demonstrated (Muniz et al., 2018).

Analyses at high resolution by both SEM (Figures $2 \mathrm{~A}, \mathbf{A i}, \mathbf{C}$ ) and TEM (Figures 2B,D) revealed the ultrastructure of
EETs being released from cytolytic eosinophils. In three dimensions (3D), EETs appeared as typical elongated DNA fibers (Figures 2A,Ai), while in situ, TEM images of adhered cells showed the two-dimensional appearance of the extruded EETs, which covered large areas outside the cells (Figures 2B colored in purple, 2D). A. fumigatus conidia entrapped by EETs were observed in 3D (Figures $\mathbf{2 A}, \mathbf{A i}, \mathbf{C}$ colored in green) and in thin sections by TEM, which revealed that the fungus cell wall was completely involved in the DNA ETs (Figures 2B,D). Free extracellular granules (FEGs) with preserved limiting membranes and typical morphology represented by an electrondense core surrounded by an electron-lucent matrix were frequently observed in association with cytolytic eosinophils, thus demonstrating that the EETosis triggered by A. fumigatus leads to the release of nearly intact granules (Figures 2Ai in yellow, 2D). Quantitative TEM of 54 randomly acquired cell sections demonstrated that most eosinophils $(87.2 \%)$ in interaction with $A$. fumigatus were cytolytic, with morphological changes typical of EETosis.

\section{Release of EETs in Response to A. fumigatus Involves Src Kinase Family Activation}

We previously showed that A. fumigatus-induced EETs release is dependent on integrin CD11b and Syk kinases (Muniz et al., 2018). Syk and Src kinases have been shown to mediate cell signaling via different classes of receptors involved in fungal recognition, including integrins (Mocsai et al., 2002, 2006). Thus, the role of Src kinases in A. fumigatus-induced EETs release was investigated. In the presence of PP2 $(10 \mu \mathrm{M})$, which is known to inhibit a broad spectrum of Src kinases, the release of extracellular DNA traps by eosinophils was abolished (Figure 3A). Confocal fluorescence microscopy confirmed these results (Figure 3B).

\section{Release of EETs in Response to A. fumigatus Requires the PI3 Kinase, Akt and p38-MAPK Signaling Pathways}

PI3K has been described as involved in the process of extracellular DNA trap release in neutrophils and eosinophils in response to different stimuli (Behnen et al., 2014; DeSouza-Vieira et al., 2016; Germic et al., 2017; Silva et al., 2019). Using fluorimetry (Figure 4A) and confocal fluorescence microscopy (Figure 4B), we observed that in the presence of $100 \eta \mathrm{M}$ wortmannin, a panPI3K inhibitor, EETs release in response to A. fumigatus was abolished. Class IA PI3K has been described as important for neutrophil extracellular DNA trap (NETs) (DeSouza-Vieira et al., 2016; Silva et al., 2019) and has been implicated as critical in different eosinophil responses (Kang et al., 2012; Saito et al., 2014). More specifically, class I PI3K $\delta$ has been described as critical for neutrophil extracellular trap release in response to A. fumigatus conidia (Silva et al., 2019) and Leishmania (DeSouza-Vieira et al., 2016), as well as for eosinophil trafficking, migration and morphology (Kang et al., 2012). Thus, the role of the class I PI3K family and the class I PI3K $\delta$ isoform in EETs release in response to A. fumigatus was assessed. As wortmannin does not distinguish among PI3K classes, we subsequently used 

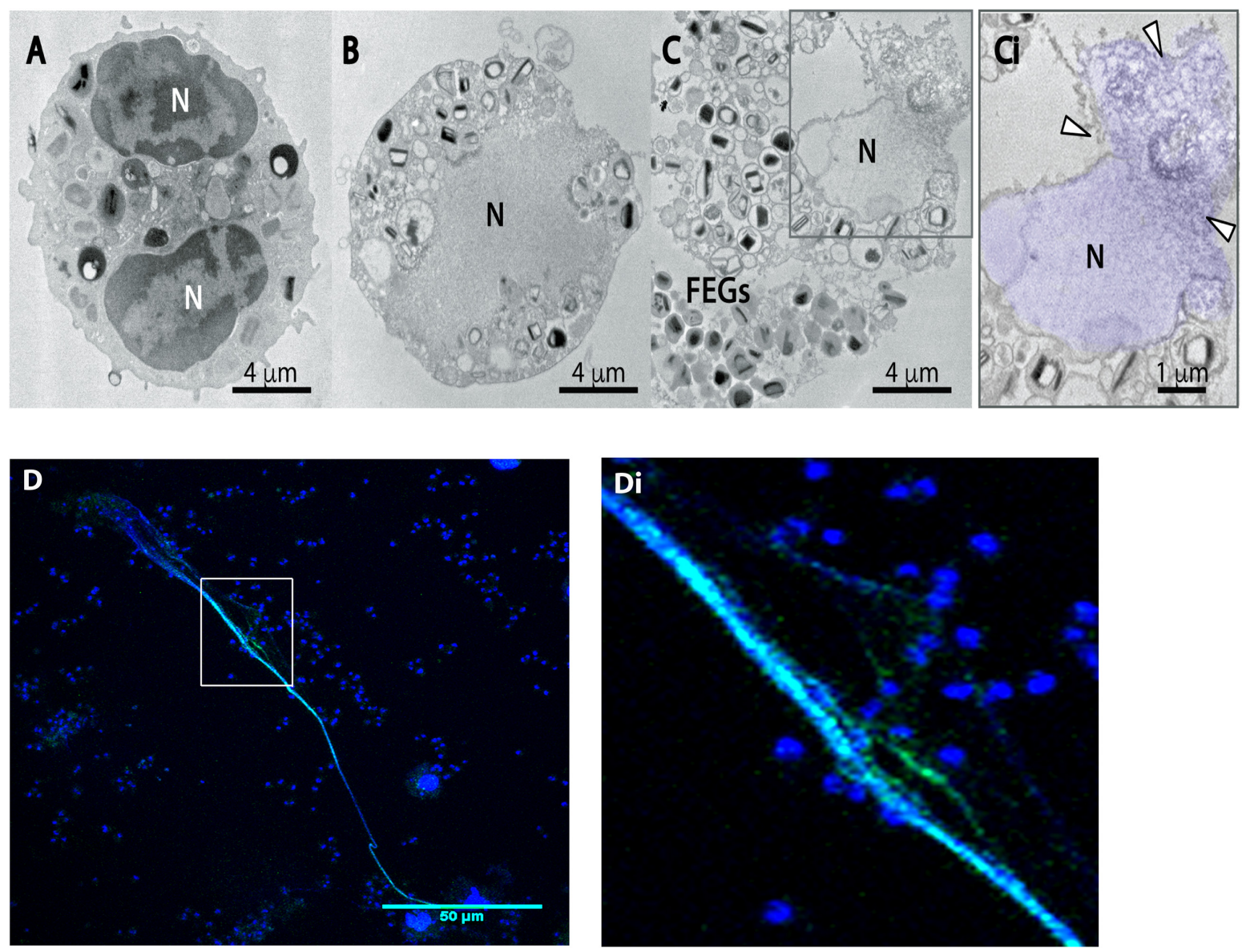

FIGURE 1 | Human eosinophils exposed to A. fumigatus show typical EETosis-associated nuclear changes and release chromatin-citrullinated histone EETs. Human eosinophils were stimulated with $A$. fumigatus conidia (cell:fungus ratio of 1:10) for $6 \mathrm{~h}$ (A) A representative unstimulated eosinophil with a typical bilobulated nucleus $(\mathrm{N})$ and well-defined euchromatin and heterochromatin. (B,C,Ci) After interaction with the fungal conidia, eosinophil nuclei undergo delobulation, disintegration of the nuclear envelope, chromatin decondensation/expansion (colored in purple) and release of extracellular traps [arrowheads in panel (Ci)]. Most free extracellular granules (FEGs) maintain their morphology. (D) EETs and citrullinated histone colocalization are shown by confocal fluorescence microscopy after staining for DNA (Hoechst, blue) and anti-citrullinated H3 histone antibodies (green). Panel (Di) is the boxed area at a higher magnification. Representative images of 3 independent experiments $(n=3)$.

the compound AS605240, which at $10 \mu \mathrm{M}$ is an inhibitor of class I PI3K. We verified that $10 \mu \mathrm{M}$ AS605240 completely inhibited EETs release (Figure 4C, left panel). Confocal fluorescence microscopy studies in which the samples were stained for DNA (Sytox Green, green) confirmed these findings (Figure 4D). In the presence of a selective PI3K $\delta$ inhibitor ( $1 \mu \mathrm{M}$ IC87114), we observed that the release of EETs in A. fumigatus-stimulated human eosinophils was inhibited (Figures 4C, right panel and 4D), suggesting that the process is dependent on the PI3K p110 subunit.

Akt kinase is commonly observed as a downstream activation molecule in the class I PI3K pathway (Hawkins et al., 2010). In addition, the participation of Akt has been demonstrated in the context of NETs release following immunocomplex recognition and signaling via Mac-1 (Behnen et al., 2014). Thus, we aimed to investigate the role of Akt in EETs release in response to A. fumigatus. As observed by fluorimetry (Figure 5A) and confocal fluorescence microscopy (Figure 5C), when we blocked the Akt signaling pathway via its inhibitor (iAkt VIII, $2.6 \mu \mathrm{M}$ ), the eosinophils did not release EETs.

p38-MAPK is known to be involved in the release of NETs in response to immune complexes (Behnen et al., 2014), calcium ionophores and PMA (Douda et al., 2015). Therefore, we investigated whether p38-MAPK was involved in A. fumigatusinduced EETs release. We found that compound SB202190 $(10 \mu \mathrm{M})$ inhibited the process of EETs release (Figure 5B). Confocal fluorescence microscopy confirmed the fluorimetric findings (Figure 5C).

\section{Release of EETs in Response to A. fumigatus Requires Calcium}

Calcium increase in leukocytes is intimately associated with the pro-inflammatory functions of these cells (Dixit and Simon, 2012). Therefore, we tested the impact of the calcium chelator BAPTA-AM on the process of A. fumigatus-induced EETs release. 



FIGURE 2 | Extracellular traps released from cytolytic eosinophils entrap conidia from A. fumigatus. Human eosinophils were stimulated with A. fumigatus conidia (cell: fungus ratio of 1:10) for $6 \mathrm{~h}$ and processed for conventional TEM and SEM. (A,Ai,C) SEM and (B,D) TEM revealed eosinophil extracellular traps (ETs) composed of fibers of DNA (highlighted in purple) emerging from cytolytic human eosinophils and entrapping conidia (colored in green). Note in a thin section (B) that the fungal cell wall is completely surrounded by eosinophil ETs. Eosinophil ETs are decorated with free extracellular granules (FEGs) seen in both 3D [Panels (A,Ai) in yellow] and two dimensions (D). The typical eosinophil granule ultrastructure with an electron-dense core and less dense matrix is observed (D). 




B
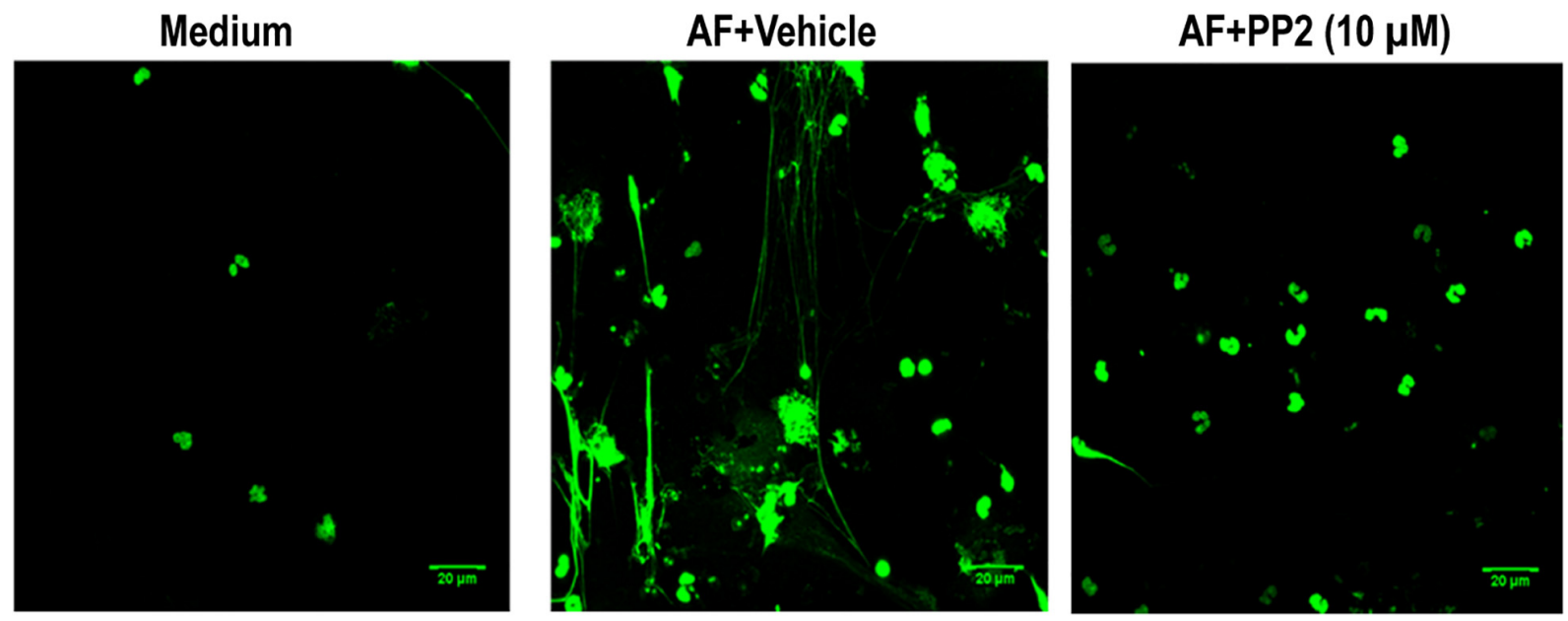

FIGURE 3 |A. fumigatus-induced EETs release depends on the Src kinase family. Human eosinophils were pretreated with a Src kinase family inhibitor (PP2) $(10 \mu \mathrm{M})$, or its vehicle (DMSO) for $30 \mathrm{~min}$ and were subsequently stimulated with $A$. fumigatus conidia (cell: fungus ratio of 1:10) for $6 \mathrm{~h}$. (A) EETs were quantified in the samples using a fluorescence microplate reader after Sytox Green addition $(5 \mu \mathrm{M})$. The graph represents the mean \pm SEM of 4 independent experiments from different donors. ${ }^{*} P<0.05$ compared to the non-stimulated sample (medium); $\# P<0.05$ compared to AF + vehicle; one-way ANOVA followed by the Newman-Keuls test. (B) Confocal fluorescence microscopy of human eosinophils pretreated with PP2 (10 $\mu \mathrm{M}$ ) or its vehicle (DMSO) for 30 min and subsequently stimulated with $A$. fumigatus conidia (cell: fungus ratio of 1:10) for $6 \mathrm{~h}$ after staining for DNA (Sytox Green, green). Representative images of 4 independent experiments $(n=4)$. AF $=$ Aspergillus fumigatus.

We observed a complete inhibition of EETs release (Figure 6A). Accordingly, fluorescence microscopy confirmed the prevention of fungal-induced EETs extrusion (Figure 6B).

\section{PAD4-Mediated Histone Citrullination Is Dispensable for $A$. fumigatus-Induced EETs Release}

In this study (Figure 1D) and in a previous study (Muniz et al., 2018), we showed that EETs released in response to A. fumigatus were associated with citrullinated histone $\mathrm{H} 3$. Histone citrullination is considered to play an essential role in the nuclear-derived EET formation mediated by the action of PAD4 (Li et al., 2010; Rohrbach et al., 2012; Lewis et al.,
2015; Kim et al., 2020), although some controversy remains about the relative importance of PAD4 for ETs release (Neeli and Radic, 2013; Kenny et al., 2017; Claushuis et al., 2018; Guiducci et al., 2018; Silva et al., 2019; Thompson-Souza et al., 2020). Thus, using fluorimetry (Figure 7A) and confocal fluorescence microscopy (Figure 7B), we observed that in the presence of GSK484 $(10 \mu \mathrm{M})$, a selective PAD4 inhibitor, EETs release in response to A. fumigatus was not inhibited (cell: fungal ratio of 1:10, $6 \mathrm{~h}$ ). Citrullinated histone $\mathrm{H} 3$ expression was increased in the presence of A. fumigatus and negatively modulated in the presence of GSK484 $(10 \mu \mathrm{M})$, as assessed by immunoblotting (Figure 7C). Interestingly, similar EET-like structures were observed in eosinophils pretreated with the PAD4 inhibitor and further stimulated with A. fumigatus; however, 

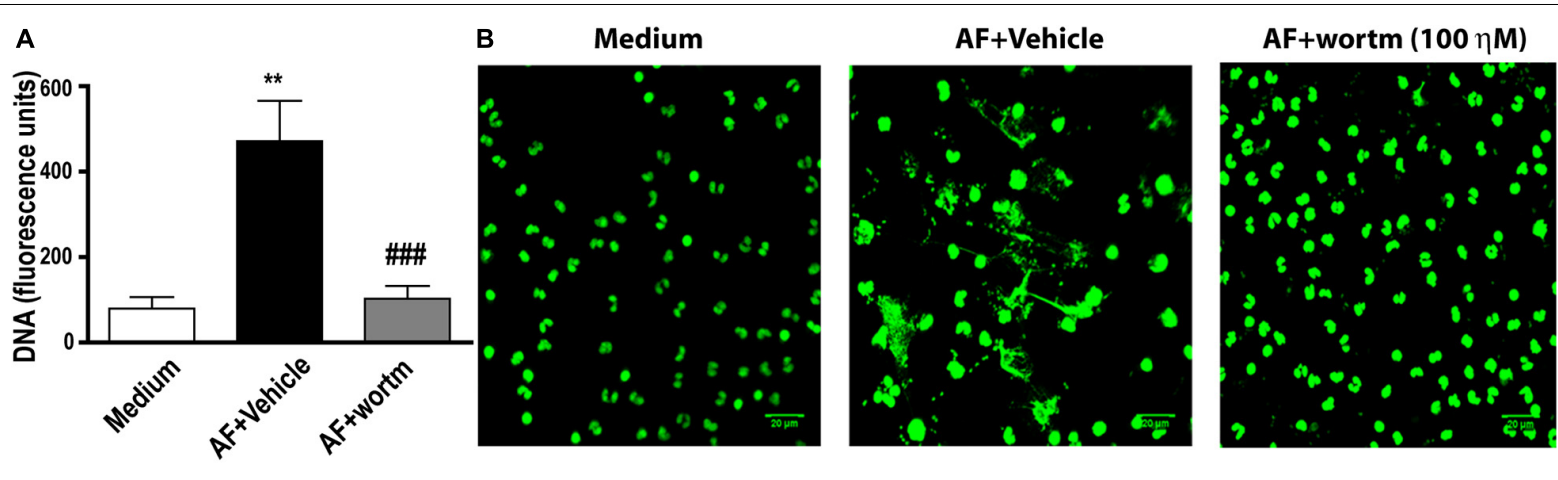

C
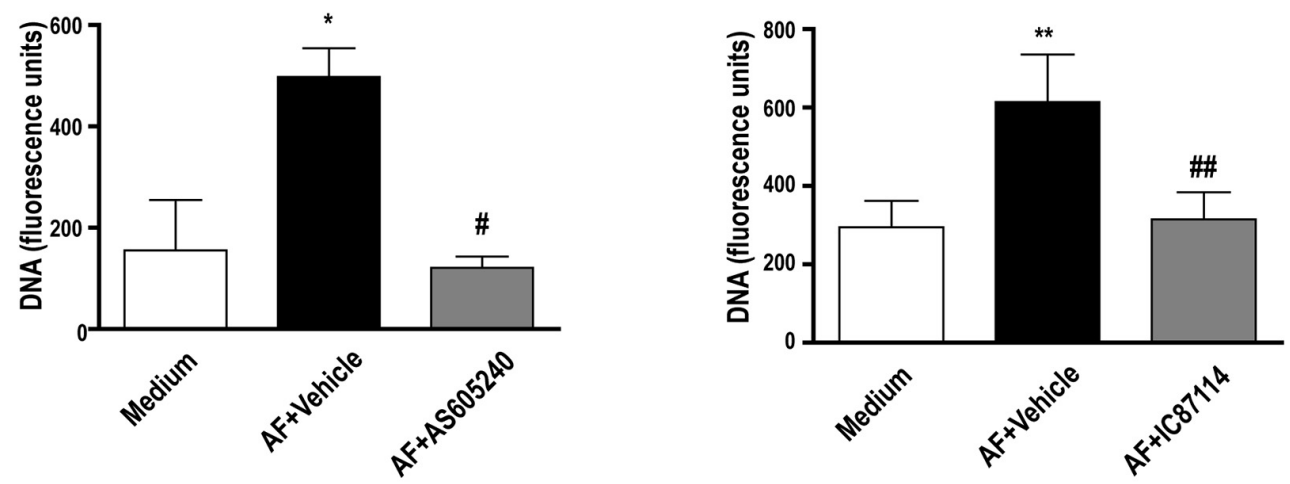

D
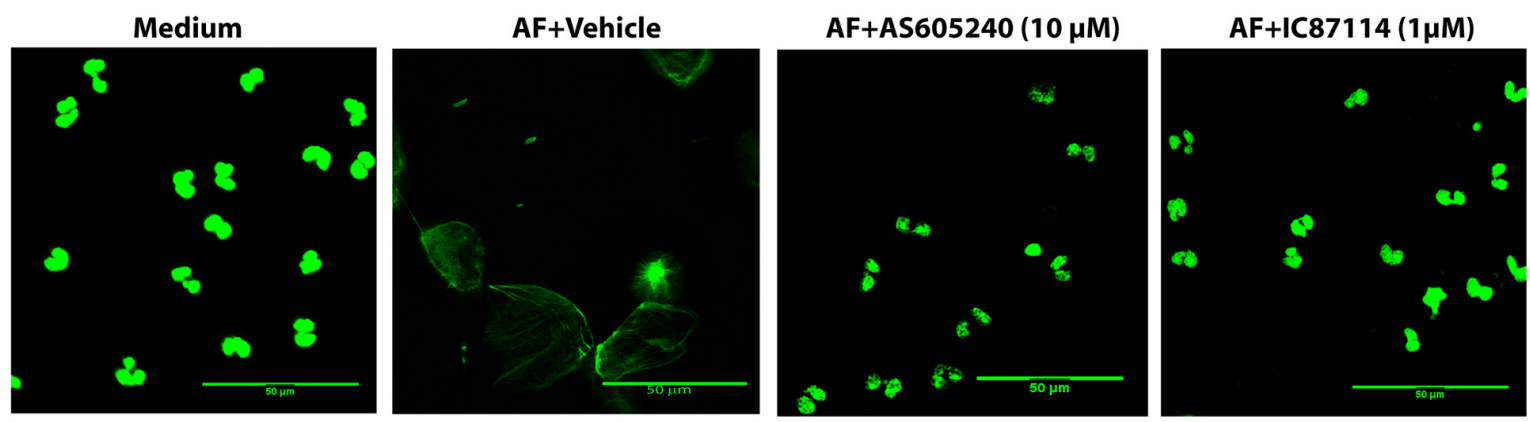

FIGURE $4 \mid$ A. fumigatus-induced EETs release requires PI3 kinase activation. Human eosinophils were pretreated with $(\mathbf{A}, \mathbf{B})$ the pan-PI3K inhibitor wortmannin

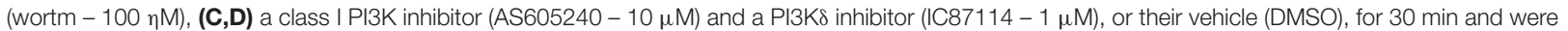
subsequently stimulated with $A$. fumigatus conidia (cell: fungus ratio of 1:10) for 6 h. (A,C) EETs were quantified in the samples using a fluorescence microplate reader after Sytox Green addition (5 $\mu$ M). The graphs represents the mean \pm SEM of 3 (wortm), 3 (AS605240) and 7 (IC87114) independent experiments from different donors. ${ }^{*} P<0.05$ and ${ }^{* *} P<0.01$ compared to the non-stimulated sample (medium); $\# P<0.05, \# \# P<0.01$, \#\#\# $P<0.001$ compared to $\mathrm{AF}+$ vehicle condition; one-way ANOVA followed by the Newman-Keuls test. (B,D) Confocal fluorescence microscopy of human eosinophils pretreated with (B) $100 \eta \mathrm{M}$ wortmannin, (D) $10 \mu \mathrm{M}$ AS605240 and $1 \mu \mathrm{M}$ IC87114 or their respective vehicle dilutions (DMSO) for 30 min and subsequently stimulated with A. fumigatus conidia (cell: fungus ratio of 1:10) for $6 \mathrm{~h}$ after staining for DNA (Sytox Green, green). Representative images of 3 (wortm), 3 (AS605240) and 7 (IC87114) independent experiments $(n=3,3$ and 7$)$. AF $=$ Aspergillus fumigatus.

citrullinated histone $\mathrm{H} 3$ sites were not detectable (Figure 7D, EETs stained by Hoechst in blue and by anti-citrullinated histone $\mathrm{H} 3$ antibodies in green).

\section{Fungus Viability Is Dispensable for}

\section{A. fumigatus-Induced EETs Release}

To evaluate whether A. fumigatus conidia viability is crucial for the process of EETs release, we stimulated eosinophils with both viable and PFO-fixed A. fumigatus conidia. As shown in
Figure 8, eosinophils responded by releasing EETs when cocultured with either live or fixed A. fumigatus conidia (cell: fungal ratio of $1: 10,6 \mathrm{~h}$ ).

\section{DISCUSSION}

Eosinophils are the major leukocytes involved in ABPA, which is the most prevalent fungal allergic manifestation among 


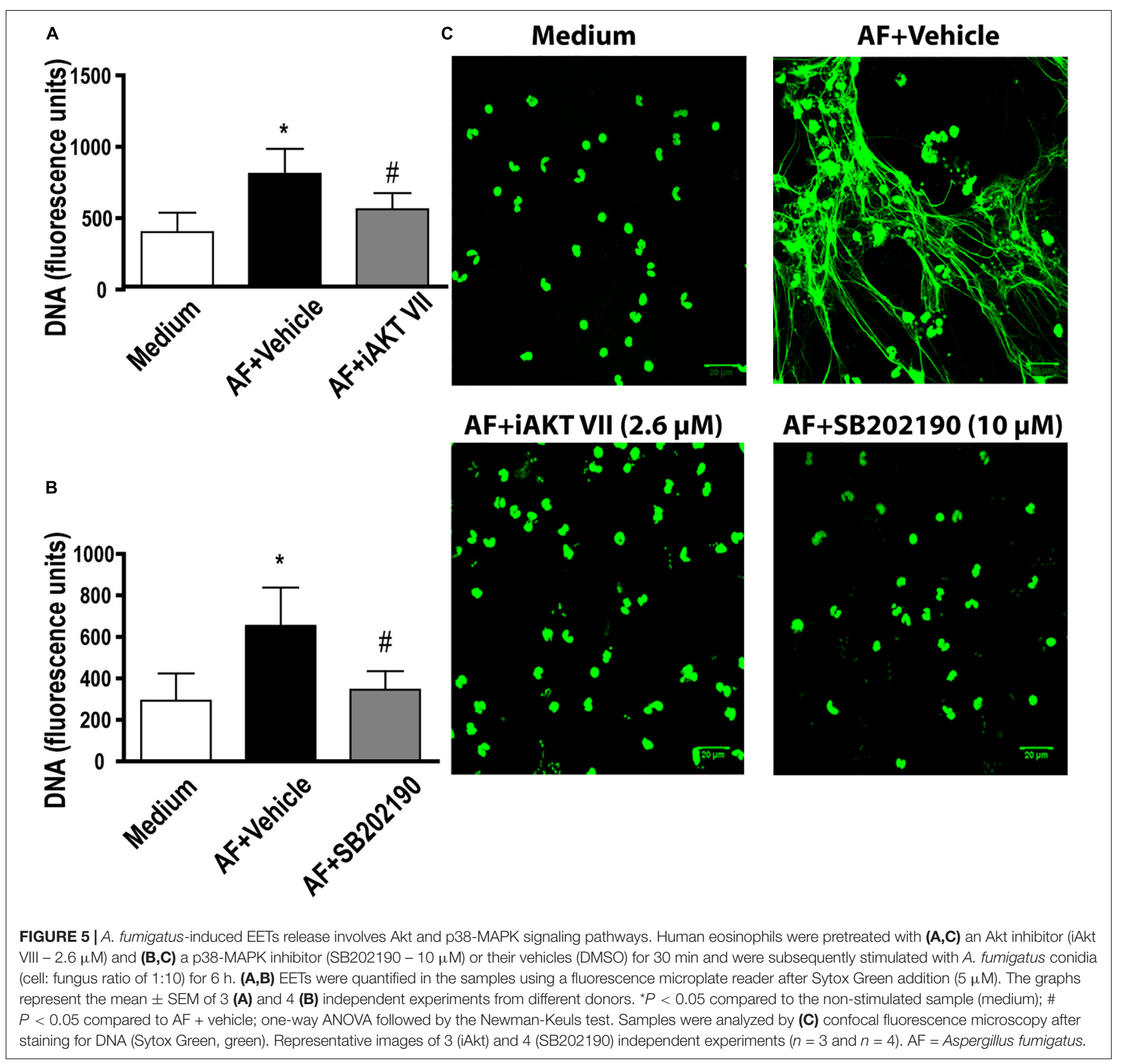

ABPMs (Shah and Panjabi, 2002; Chowdhary et al., 2014). Thus, studies that contribute to a better understanding of ABPA pathology and can elucidate possible therapeutic targets for patient treatment are extremely relevant. Previous studies have shown that EETs are present in the mucus plugs of ABPA patients and that human eosinophils release EETs in response to A. fumigatus conidia in vitro (Muniz et al., 2018; Ueki et al., 2018). Nevertheless, efforts to understand eosinophil-A. fumigatus recognition and the mechanisms that drive this interaction are still in progress. Here, we demonstrated by both TEM and SEM that eosinophils responding to A. fumigatus stimulation present prominent morphological alterations typical of EETosis. Moreover, A. fumigatus-induced EETs release depends on the calcium, Src, PI3K, p38 MAPK and Akt signaling pathways. Interestingly, we determined that human eosinophils release EETs in response to A. fumigatus independently of PAD4 and histone citrullination through a process in which fungus viability is dispensable (Figure 9).

EETosis with a cytolytic profile and extrusion of extracellular traps has increasingly been identified in several eosinophilic diseases (Ueki et al., 2016a,b, 2018). This process of cell death associated to ETs release is morphologically distinct from other classic cell death processes, such as apoptosis and necrosis (Fuchs et al., 2007; Brinkmann and Zychlinsky, 2012), and has been associated with different leukocytes, especially neutrophils (Brinkmann et al., 2004), mast cells 


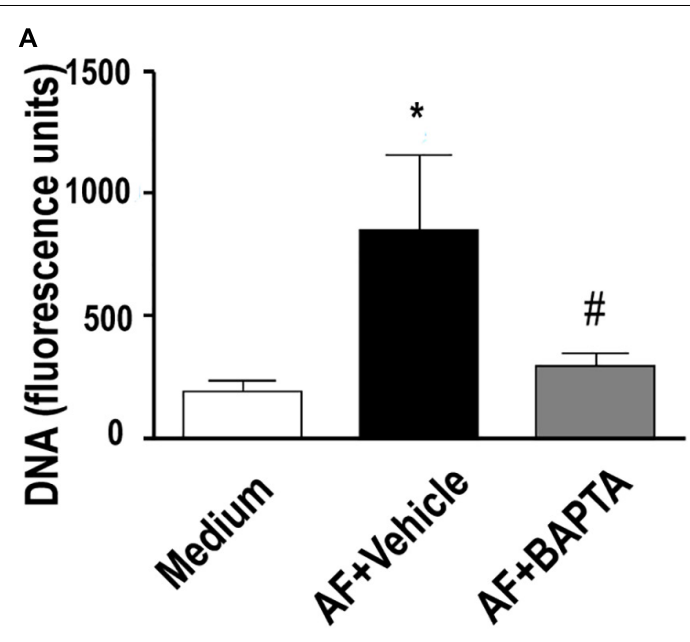

B

Medium



AF+Vehicle

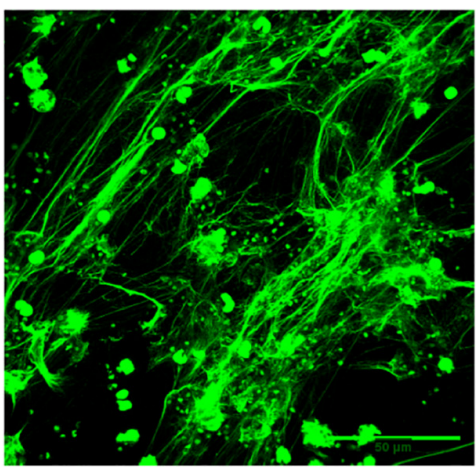

AF+BAPTA $(10 \mu M)$

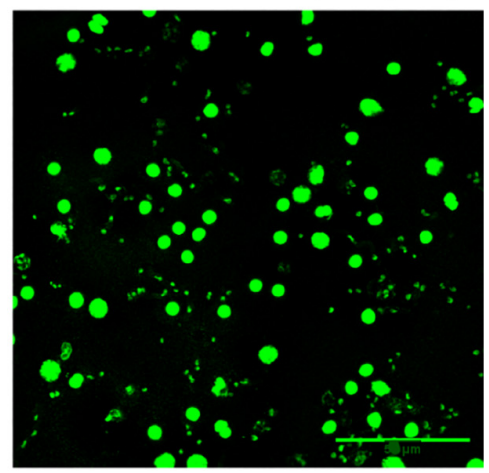

FIGURE 6 |A. fumigatus-induced release of EETs depends on calcium. Human eosinophils were pretreated with the calcium chelator BAPTA-AM (10 $\mu$ M) or its vehicle (DMSO) for 30 min and were subsequently stimulated with $A$. fumigatus conidia (cell: fungus ratio of 1:10) for 6 h. (A) EETs were quantified in the samples using a fluorescence microplate reader after Sytox Green addition $(5 \mu \mathrm{M})$. The graph represents the mean \pm SEM of 3 independent experiments from different donors. ${ }^{*} P<0.05$ compared to the non-stimulated sample (medium); \#P < 0.05 compared to AF + vehicle; one-way ANOVA followed by the Newman-Keuls test. (B) Confocal fluorescence microscopy of human eosinophils pretreated with BAPTA-AM (10 $\mu$ M) or its vehicle (DMSO) for 30 min and subsequently stimulated with A. fumigatus conidia (cell: fungus ratio of 1:10) for $6 \mathrm{~h}$ after staining for DNA (Sytox Green, green). Representative images of 4 independent experiments ( $n=4$ ). $\mathrm{AF}=$ Aspergillus fumigatus.

(von Kockritz-Blickwede et al., 2008) and eosinophils (Ueki et al., 2013). Here, we used high-resolution TEM to characterize intracellular events associated with EETosis. Our TEM findings revealed that $A$. fumigatus-stimulated eosinophils elicited nuclear changes typical of EETosis (decondensation, delobulation/rounding, disruption of nuclear envelope, chromatin expansion in the cytoplasm and further release of EETs) (Figure 1). These processes are well characterized in neutrophils (Fuchs et al., 2007), but are poorly understood in human eosinophils. In contrast to the process of ETosis in neutrophils (termed NETosis), which leads to the release of granule contents mixed with released chromatin (Brinkmann et al., 2004; Fuchs et al., 2007), EETosis enables the release of clusters of FEGs, with preserved morphology and contents, together with EETs. Our ultrastructural results showing FEGs by both TEM (Figures 1C, 2D) and SEM (Figures 2A,Ai) are in accordance with previous works demonstrating that EETosis induced by different stimuli, including the lipid mediator lysophosphatidylserine and A. fumigatus conidia, occurs in the presence of punctual MBP labeling (indicative of intact granules) and in the absence of linear immunostaining for MBP or ECP (indicative of disrupted granules) (Ueki et al., 2013; Muniz et al., 2018; Kim et al., 2020). This means that distinct mechanisms are operating in neutrophils and eosinophils in the process of granule product release in association with DNA traps during ETosis. For eosinophils, FEGs are secretory-competent organelles acting as "cluster bombs" that selectively release proteins under specific stimuli (Neves et al., 2008; Ueki et al., 2013). However, the consequences of these secretory entities associated with EETs still require clarification. 



FIGURE 7 | Histone citrullination mediated by PAD4 is dispensable for A. fumigatus-induced EETs release. Human eosinophils were pretreated with the PAD4 selective inhibitor GSK484 (10 $\mu \mathrm{M})$ or its vehicle (DMSO) for $30 \mathrm{~min}$ and were subsequently stimulated with $A$. fumigatus conidia (cell: fungus ratio of 1:10) for $6 \mathrm{~h}$. (A) EETs were quantified in the samples using a fluorescence microplate reader after Sytox Green addition (5 $\mu \mathrm{M})$. The graph represents the mean \pm SEM of 3 independent experiments from different donors. ${ }^{\star} P<0.05$ compared to the non-stimulated sample (medium); one-way ANOVA followed by the Newman-Keuls test. (B) Samples were analyzed by confocal fluorescence microscopy after staining for DNA (Sytox Green, green). Representative images of 3 independent experiments $(n=3)$. Histone citrullination was evaluated by $(\mathbf{C})$ immunoblotting and (D) confocal fluorescence microscopy after staining for DNA (Hoechst, blue) and anti-citrullinated H3 histone antibodies (green). Representative immunoblotting images of 3 independent experiments ( $n=3$ ). AF = Aspergillus fumigatus.
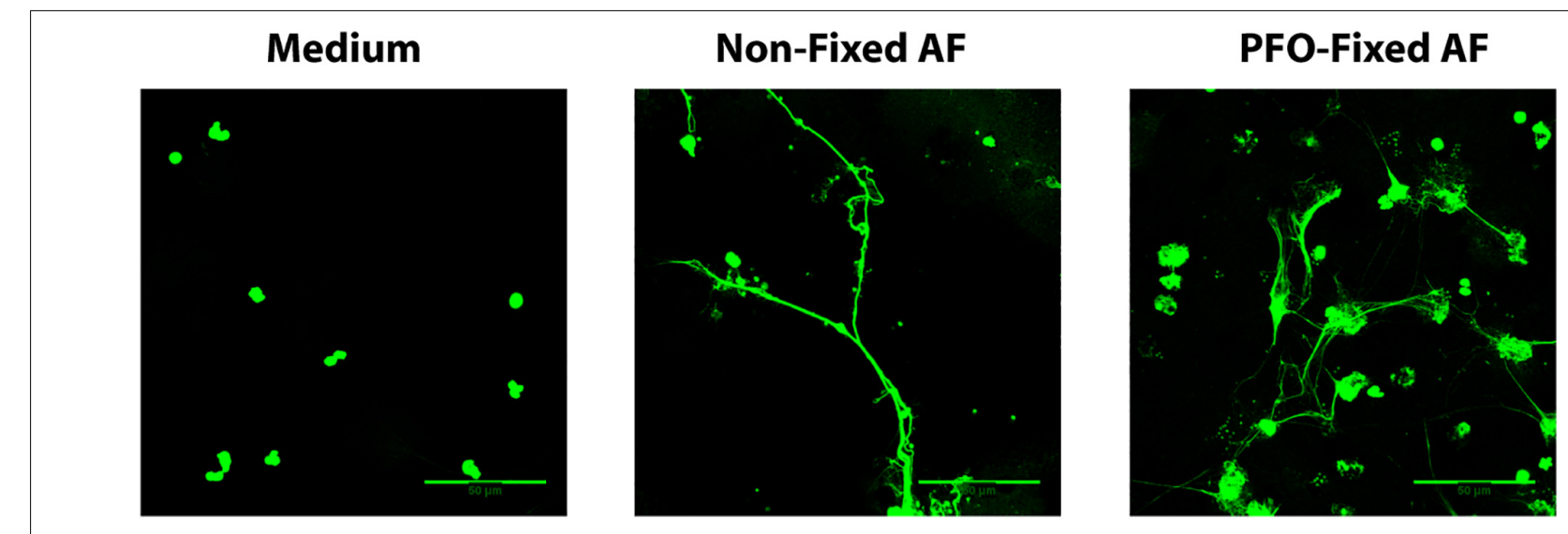

FIGURE 8 | Fungus viability is dispensable for A. fumigatus-induced EETs release. Human eosinophils were stimulated with both viable and paraformaldehyde (PFO)-fixed A. fumigatus conidia (cell: fungus ratio of 1:10, 6 h). Samples were analyzed by confocal fluorescence microscopy after staining for DNA (Sytox Green, green). Representative images of 4 independent experiments $(n=4)$. AF $=$ Aspergillus fumigatus.

The capacity of chromatin to actively participate in NETosis is now recognized (Neubert et al., 2018), in addition to its classical role in regulating gene expression. During NETosis, after certain signaling events and enzymatic reactions (including histone citrullination and phosphorylation events), the chromatin expands, which drives the rupture of the nuclear envelope, determining the point of no return. Here, we noted the same event for human eosinophils undergoing EETosis. Although signaling molecules are usually the focus of studies on cell activation processes, recent works have demonstrated that chromatin changes are crucial in determining cell fate (Neubert et al., 2018). Thus, our ultrastructural observations bring a new appreciation of the importance of linking intracellular signaling pathways to nuclear entities and structural protein modifications to better delineate a stimulus-specific cell activation process. 




FIGURE 9 | (1) A. fumigatus conidia-human eosinophil interaction triggers the activation of Src that will phosphorylate Syk tyrosine kinases. Then, PI38K will be activated followed by Akt, probably with the participation of calcium. p38 MAPK will also likely be activated downstream the PI3K signaling (2) This signaling leads to histone citrullination mediated by PAD4 and chromatin decondensation. However, PAD4 and H3 citrullination are not essential for EETs extrusion. (3) Rupture of the nuclear envelope and plasma membrane allowed the release of chromatin-formed EETs that entrap A. fumigatus conidia and free extracellular granules (FEGs).

We previously demonstrated that intracellular signaling involved in the release of EETs in response to A. fumigatus is Syk- and CD11b $\beta 2$-integrin-dependent (Muniz et al., 2018). Src and Syk kinases have been implicated in the cell signaling of various classes of receptors involved in fungal molecule recognition, including integrins (Mocsai et al., 2002, 2006; Jakus et al., 2007) and C-type lectins (Rogers et al., 2005; Kerrigan and Brown, 2010). Src-family kinases are involved in $\beta_{2}$ integrin-mediated responses in which the Src kinases are implicated in Syk phosphorylation in neutrophils (Mocsai et al., 2006). In line with these findings, our results reveal that A. fumigatus-induced EETs release is blocked in the presence of a Src inhibitor. Additionally, in agreement with our findings, neutrophils respond to A. fumigatus conidia by releasing NETs in a Syk-Src-dependent signaling pathway (Silva et al., 2019).

PI3Ks are enzymes that catalyze the phosphorylation of one or more inositol phospholipids in the 3-position of the inositol ring. PI3Ks can be divided into classes I, II, and III. Class IA PI3Ks, which include PI3K $\alpha, \beta$, and $\delta$, are activated by stimulation of tyrosine kinase-based receptors. PI3K $\gamma$, the only member of class IB, is activated by stimulation of GPCR subunits (Vanhaesebroeck et al., 2010). We found that both a nonselective (wortmannin) and a class I-selective (AS605240, 10 $\mu \mathrm{M})$ PI3K inhibitor blocked A. fumigatus-induced EET release. Because there have been many studies of wortmannin as a nonselective inhibitor of the different PI3K classes and of other possible targets (Makni-Maalej et al., 2013; Germic et al., 2017), we additionally used the compound AS605240. AS605240 at $10 \mu \mathrm{M}$ has been reported as an inhibitor of class I PIKs but is unable at this concentration to distinguish between class $\mathrm{A}$ (PI3K $\alpha, \beta$ and $\delta$ ) and B (PI3K $\gamma$ ) (Sadhu et al., 2003; Silva et al., 2019). In mammals, class I PI3Ks are present in all cell types, including eosinophils, with PI $3 \mathrm{~K} \delta$ and $\gamma$ highly enriched in leukocytes (Kok et al., 2009). As mentioned, we have previously described the dependence of A. fumigatus-induced EET release on Syk signaling (Muniz et al., 2018). Syk is a tyrosine kinase that is crucial in the signaling pathways mediated by Dectin-1 and the $\beta_{2}$ integrin CD11b/CD18 (Mocsai et al., 2002; Rogers et al., 2005). Taking in account that receptors utilizing protein tyrosine kinase activation are known to be more related to the activation of class IA PI3Ks (PI3K $\alpha, \beta$, and $\delta$ ), we investigated the role of class I PI3K $\delta$ in A. fumigatus-induced EET release. We observed that compound IC-87114 at $1 \mu \mathrm{M}$ (concentration known to be selective for the class I $\delta$ isoform) (Sadhu et al., 2003; Silva et al., 2019) completely inhibited EETs release. Indeed, the importance of PI3K $\delta$ in eosinophils and in experimental models of allergic inflammation has been previously reported (Lee et al., 2006; Nashed et al., 2007; Kang et al., 2012). Kang and colleagues demonstrated that treatment with ICI87114 reduced murine bone marrow-derived eosinophil adhesion and Mac-1 expression and had inhibitory effects on eotaxin-1-induced chemotaxis and shape change (Kang et al., 2012). However, the authors used $10 \mu \mathrm{M}$ ICI87114. In our studies, we used $1 \mu \mathrm{M}$ ICI87114. Some studies suggest that $10 \mu \mathrm{M}$ ICI87114 might also have prominent effects on PI3K $\gamma$ (Sadhu et al., 2003; Silva et al., 2019). Regarding the PI $3 \mathrm{~K} \gamma$ isoform, some important effects have also been described in human eosinophils but are related to the activation of GPCRs (Saito et al., 2014). Saito and colleagues described the 
effects of specific inhibition of the PI $3 \mathrm{~K} \gamma$ isoform on human eosinophil chemotaxis, adherence and degranulation induced by eotaxin (Saito et al., 2014). Since PI3K $\gamma$ signaling is associated with GPCRs (such as CCR3), whereas PI3K $\alpha, \beta$, and $\delta$ are activated by receptor tyrosine kinase, it is possible that PI $3 \mathrm{~K} \gamma$ and $\delta$ isoforms might have distinct roles in eosinophil intracellular signaling and function depending on the stimuli and the cognate receptor involved. In fact, PI3K activation has been implicated as crucial for ROS generation-induced DNA trap release in eosinophils and neutrophils stimulated with GM-CSF and C5a or with low concentrations of PMA (Germic et al., 2017); and in neutrophils stimulated with immobilized immune complexes (Behnen et al., 2014). In contrast, other studies have pointed that ROS and PI3K is dispensable for lysophosphatidylserineinduced EETs extrusion (Kim et al., 2020). The PI3K $\delta$ isoform specifically has been described as critically involved in NETs release in response to Leishmania amazonensis (DeSouza-Vieira et al., 2016) and A. fumigatus (Silva et al., 2019) in a signaling pathway upstream of ROS production. In contrast, the PI3K $\gamma$ isoform is not involved in A. fumigatus-induced NETs release (Silva et al., 2019).

The activation of Akt has been reported to be the downstream target of PI3K in various cells, including eosinophils (Alessi et al., 1997; Machida et al., 2005; Hawkins et al., 2010). The participation of Akt has been demonstrated in the context of NETs release following immunocomplex recognition and signaling via Mac-1 (Behnen et al., 2014). Moreover, it has been demonstrated that PMA-induced NETs formation is dependent on Akt activation, which suppresses apoptosis via the inhibition of caspases (Douda et al., 2014). In agreement with these findings, we found that the release of EETs in response to A. fumigatus requires the PI3 kinase and Akt signaling pathways. Behnen and colleagues showed that CR3 (CD11b/CD18) activation through the recognition of immunocomplexes by the Fc $\gamma$ RIIIB receptor induces NETs release via the Src/Syk, PI3K/Akt, p38 MAPK, and ERK1/2 signaling pathways (Behnen et al., 2014). The involvement of p38 MAPK in NETs release induced by different stimuli, such as bacteria or PMA, was previously reported (Keshari et al., 2013; Behnen et al., 2014; Douda et al., 2015; Ma et al., 2018). In agreement with these studies, we found that the release of EETs was inhibited when eosinophils were pretreated with SB202190, suggesting the involvement of p38MAPK signaling in A. fumigatus-induced EETs release.

As we observed that A. fumigatus-induced EETs release triggered the Src/Syk, PI3K/Akt and p38 MAPK signaling pathways, we also examined calcium. Changes in leukocyte calcium levels have been consistently related to several leukocyte functions, including cell adhesion, chemotaxis and degranulation, among others (Dixit and Simon, 2012; Hann et al., 2020). The relationship between calcium and ETosis has been supported by different studies in eosinophils, but mostly by studies in neutrophils (Parker et al., 2012; Gupta et al., 2014; Ueki et al., 2016a; Kenny et al., 2017; de Bont et al., 2018). Moreover, the activation of Akt has been found to be regulated by an elevation of calcium during the NETosis process (Douda et al., 2014). Thus, our finding that the calcium chelator BAPTA-AM inhibited EETs release induced by A. fumigatus corroborates these previous observations. Ueki and colleagues found that EDTA inhibited the EETs extrusion induced by A23187, PMA, or immobilized IgG in human eosinophils (Ueki et al., 2016a). In neutrophils, Kenny and colleagues demonstrated the relevance of intracellular calcium for PMA-induced NET production by showing a strong inhibition of NETosis after treating neutrophils with BAPTA-AM (Kenny et al., 2017). In agreement with this observation, another work also provided evidence that external calcium is dispensable for NETs extrusion induced by PMA (Douda et al., 2015). In contrast, a different study showed that IL-8-mediated NET formation requires calcium fluxes from both intracellular and extracellular pools, while only extracellular calcium appeared to be important for PMA-mediated NET generation (Gupta et al., 2014). Accordingly, ionomycin and other calcium ionophores have been widely used as known inducers of NETs and EETs (Douda et al., 2015; Ueki et al., 2016a). In this context, it is clear that calcium plays a crucial role in A. fumigatus-induced ETTs extrusion. However, whether calcium is important for Akt activation during this EETosis process or which is the major source of calcium (intracellular or extracellular or both) are questions still to be answered.

Although several studies have implicated a role for PAD4 in histone citrullination and chromatin decondensation in the process of ETosis (Wang et al., 2009; Li et al., 2010; Lewis et al., 2015; Van Avondt and Hartl, 2018; Kim et al., 2020), others have suggested that PAD4 might not be essential for this process even when $\mathrm{H} 3$ citrullination is reduced (Neeli and Radic, 2013; Kenny et al., 2017; Claushuis et al., 2018; Guiducci et al., 2018; Silva et al., 2019; Thompson-Souza et al., 2020). According to most ET studies, the citrullination of histone 3 by the enzyme PAD4, expressed in the nuclei of eosinophils and other granulocytes (Asaga et al., 2001; Nakashima et al., 2002; Kim et al., 2020), results in weakened DNA-histone binding, thereby facilitating the release of DNA from the nucleus and out of the cell (Van Avondt and Hartl, 2018). However, other studies have shown that histone citrullinationindependent mechanisms occur in the process of NETs release in response to Candida albicans (Guiducci et al., 2018), bacteria (Streptococcus and Klebsiella pneumoniae) (Kenny et al., 2017; Claushuis et al., 2018), Histoplasma capsulatum (ThompsonSouza et al., 2020) and A. fumigatus (Silva et al., 2019). Under our conditions, we observed that EETs generated in response to A. fumigatus exhibited histone citrullination that was PAD4dependent; however, $\mathrm{PAD} 4$ and $\mathrm{H} 3$ citrullination are not essential for EETs extrusion. In fact, the existence of NET release pathways independent of histone citrullination has been described for PMA, one of the most recognized promoters of NET release (Neeli and Radic, 2013; Kenny et al., 2017). In this context, the dependency of ETs extrusion on PAD4 and histone citrullination is questionable and might depend on the stimuli and cell type involved. One question that remains in eosinophils is which molecule is responsible for chromatin decondensation, since it can occur independently of PAD4 and histone citrullination. In neutrophils, elastase and myeloperoxidase have been described as important for this process (Papayannopoulos et al., 2010), but in eosinophils, this is a point for future investigations. Moreover, the consequences of the release of non-citrullinated 
EETs for the host immune response, for the fungus, and for ABPA development remain unknown. We previously showed that EETs do not contribute to the killing and impairment of A. fumigatus conidia (Muniz et al., 2018). Thus, the impact of noncitrullinated EETs on fungal viability is potentially not critical. However, other consequences of these non-citrullinated EETs regarding ABPA development and the host immune response cannot be discarded. In a study of Klebsiella pneumoniaeinduced pneumonia, NETs formed in the absence of PAD4 and histone citrullination did not affect bacterial growth or lung inflammation (Claushuis et al., 2018). Whether the same is valid for eosinophils or eosinophilic lung inflammation in the context of ABPA remains to be addressed. Our findings also demonstrated that $A$. fumigatus is capable of inducing EETs release independent of fungal viability. In previous works, dead A. fumigatus conidia were also capable of inducing neutrophils to release extracellular DNA traps (Bruns et al., 2010; McCormick et al., 2010). Thus, fungal cell metabolism seems to play no active role in this interaction, both in EETs and NETs formation.

In this study, we identified several components that drive EETs release in response to the fungus A. fumigatus. Based on this and previous studies (Muniz et al., 2018), we believe that the excessive release of EETs may contribute to the formation of sticky mucus, which in turn contributes to airway obstruction and lung function impairment. Furthermore, because EETs lack killing activity against $A$. fumigatus (Muniz et al., 2018), their association with clusters of functional FEGs may potentiate the pro-inflammatory roles of these structures. Thus, therapeutic interventions to avoid or degrade these DNA traps may represent an interesting approach to minimize inflammatory lung damage without major impacts on fungal clearance. In addition to clarifying mechanisms that underlie the interaction between A. fumigatus and eosinophils, these findings may help improve our understanding of ABPA pathogenesis and treatment.

\section{DATA AVAILABILITY STATEMENT}

The original contributions presented in the study are included in the article/supplementary material, further inquiries can be directed to the corresponding author/s.

\section{REFERENCES}

Agarwal, R., Chakrabarti, A., Shah, A., Gupta, D., Meis, J. F., Guleria, R., et al. (2013). Allergic bronchopulmonary aspergillosis: review of literature and proposal of new diagnostic and classification criteria. Clin. Exp. Allergy 43, 850-873. doi: 10.1111/cea.12141

Alessi, D. R., James, S. R., Downes, C. P., Holmes, A. B., Gaffney, P. R., Reese, C. B., et al. (1997). Characterization of a 3-phosphoinositide-dependent protein kinase which phosphorylates and activates protein kinase Balpha. Curr. Biol. 7, 261-269. doi: 10.1016/s0960-9822(06)00122-9

Asaga, H., Nakashima, K., Senshu, T., Ishigami, A., and Yamada, M. (2001). Immunocytochemical localization of peptidylarginine deiminase in human eosinophils and neutrophils. J. Leukoc. Biol. 70, 46-51.

Behnen, M., Leschczyk, C., Moller, S., Batel, T., Klinger, M., Solbach, W., et al. (2014). Immobilized immune complexes induce neutrophil extracellular trap

\section{ETHICS STATEMENT}

The studies involving human participants were reviewed and approved by Committee on Human Research at Clementino Fraga Filho Hospital (Federal University of Rio de Janeiro). The patients/participants provided their written informed consent to participate in this study.

\section{AUTHOR CONTRIBUTIONS}

MVB, IG, MAAD, GAT-S, VSM, and CRIV conducted the experiments and acquired and analyzed the data. MVB, RCNM, RTF, and JSN designed the research studies, analyzed the data and provided reagents. MVB and JSN wrote the manuscript. RCNM and RTF critically revised the manuscript for important intellectual content. All authors contributed to the article and approved the submitted version.

\section{FUNDING}

This work was supported by the Brazilian agencies Fundação de Amparo à Pesquisa do Estado do Rio de Janeiro (FAPERJ) (\#E-26/203.312/2017 granted to JSN) and the Conselho Nacional de Desenvolvimento Científico e Tecnológico (CNPq) (\#409057/2018-5 and \#309216/2017-6 granted to JSN; \#309734/2018-5 and 434914/2018-5 granted to RCNM). MVB (post-doc scholarship) and IG (MSc scholarship) especially thank Coordenação de Aperfeiçoamento de Pessoal de Nível Superior (CAPES) for the financial support.

\section{ACKNOWLEDGMENTS}

We thank Grasiela Ventura for technical assistance in image acquisition in the confocal microscopy facility of the Biomedical Sciences Institute (ICB, UFRJ, Brazil) and Gustavo Rocha for technical assistance in image acquisition in the scanning electron microscopy facility at Centro Nacional de Biologia Estrutural e Bioimagens (CENABIO, UFRJ, Brazil). We also thank Katiane Oliveira Vieira for technical assistance with the various experiments performed in this study.

release by human neutrophil granulocytes via FcgammaRIIIB and Mac-1. J. Immunol. 193, 1954-1965. doi: 10.4049/jimmunol.1400478

Brinkmann, V., Reichard, U., Goosmann, C., Fauler, B., Uhlemann, Y., Weiss, D. S., et al. (2004). Neutrophil extracellular traps kill bacteria. Science 303, 1532-1535. doi: 10.1126/science.1092385

Brinkmann, V., and Zychlinsky, A. (2012). Neutrophil extracellular traps: is immunity the second function of chromatin? J. Cell Biol. 198, 773-783. doi: $10.1083 /$ jcb. 201203170

Bruns, S., Kniemeyer, O., Hasenberg, M., Aimanianda, V., Nietzsche, S., Thywissen, A., et al. (2010). Production of extracellular traps against Aspergillus fumigatus in vitro and in infected lung tissue is dependent on invading neutrophils and influenced by hydrophobin RodA. PLoS Pathog. 6:e1000873. doi: 10.1371/ journal.ppat.1000873

Chow, O. A., von Kockritz-Blickwede, M., Bright, A. T., Hensler, M. E., Zinkernagel, A. S., Cogen, A. L., et al. (2010). Statins enhance formation of 
phagocyte extracellular traps. Cell Host Microbe 8, 445-454. doi: 10.1016/j. chom.2010.10.005

Chowdhary, A., Agarwal, K., Kathuria, S., Gaur, S. N., Randhawa, H. S., and Meis, J. F. (2014). Allergic bronchopulmonary mycosis due to fungi other than Aspergillus: a global overview. Crit. Rev. Microbiol. 40, 30-48. doi: 10.3109/ 1040841X.2012.754401

Claushuis, T. A. M., van der Donk, L. E. H., Luitse, A. L., van Veen, H. A., van der Wel, N. N., van Vught, L. A., et al. (2018). Role of peptidylarginine deiminase 4 in neutrophil extracellular trap formation and host defense during Klebsiella pneumoniae-induced pneumonia-derived sepsis. J. Immunol. 201, 1241-1252. doi: 10.4049/jimmunol.1800314

de Bont, C. M., Koopman, W. J. H., Boelens, W. C., and Pruijn, G. J. M. (2018). Stimulus-dependent chromatin dynamics, citrullination, calcium signalling and ROS production during NET formation. Biochim. Biophys. Acta Mol. Cell. Res. 1865(11 Pt A), 1621-1629. doi: 10.1016/j.bbamcr.2018.08.014

Denning, D. W., Pashley, C., Hartl, D., Wardlaw, A., Godet, C., Del Giacco, S., et al. (2014). Fungal allergy in asthma-state of the art and research needs. Clin. Transl. Allergy 4:14. doi: 10.1186/2045-7022-4-14

Denning, D. W., Pleuvry, A., and Cole, D. C. (2013). Global burden of allergic bronchopulmonary aspergillosis with asthma and its complication chronic pulmonary aspergillosis in adults. Med. Mycol. 51, 361-370. doi: 10.3109/ 13693786.2012.738312

DeSouza-Vieira, T., Guimaraes-Costa, A., Rochael, N. C., Lira, M. N., Nascimento, M. T., Lima-Gomez, P. S., et al. (2016). Neutrophil extracellular traps release induced by Leishmania: role of PI3Kgamma, ERK, PI3Ksigma, PKC, and [Ca2+]. J. Leukoc. Biol. 100, 801-810. doi: 10.1189/jlb.4A0615-261RR

Dixit, N., and Simon, S. I. (2012). Chemokines, selectins and intracellular calcium flux: temporal and spatial cues for leukocyte arrest. Front. Immunol. 3:188. doi: $10.3389 /$ fimmu.2012.00188

Douda, D. N., Khan, M. A., Grasemann, H., and Palaniyar, N. (2015). SK3 channel and mitochondrial ROS mediate NADPH oxidase-independent NETosis induced by calcium influx. Proc. Natl. Acad. Sci. U.S.A. 112, 2817-2822. doi: 10.1073/pnas.1414055112

Douda, D. N., Yip, L., Khan, M. A., Grasemann, H., and Palaniyar, N. (2014). Akt is essential to induce NADPH-dependent NETosis and to switch the neutrophil death to apoptosis. Blood 123, 597-600. doi: 10.1182/blood-2013-09-526707

Fuchs, T. A., Abed, U., Goosmann, C., Hurwitz, R., Schulze, I., Wahn, V., et al. (2007). Novel cell death program leads to neutrophil extracellular traps. J. Cell Biol. 176, 231-241. doi: 10.1083/jcb.200606027

Germic, N., Stojkov, D., Oberson, K., Yousefi, S., and Simon, H. U. (2017). Neither eosinophils nor neutrophils require ATG5-dependent autophagy for extracellular DNA trap formation. Immunology 152, 517-525. doi: 10.1111/ imm. 12790

Guiducci, E., Lemberg, C., Kung, N., Schraner, E., Theocharides, A. P. A., and LeibundGut-Landmann, S. (2018). Candida albicans-induced NETosis is independent of peptidylarginine deiminase 4. Front. Immunol. 9:1573. doi: 10.3389/fimmu.2018.01573

Guimaraes-Costa, A. B., Nascimento, M. T., Froment, G. S., Soares, R. P., Morgado, F. N., Conceicao-Silva, F., et al. (2009). Leishmania amazonensis promastigotes induce and are killed by neutrophil extracellular traps. Proc. Natl. Acad. Sci. U.S.A. 106, 6748-6753. doi: 10.1073/pnas.0900226106

Gupta, A. K., Giaglis, S., Hasler, P., and Hahn, S. (2014). Efficient neutrophil extracellular trap induction requires mobilization of both intracellular and extracellular calcium pools and is modulated by cyclosporine A. PLoS One 9:e97088. doi: 10.1371/journal.pone.0097088

Hann, J., Bueb, J. L., Tolle, F., and Bréchard, S. (2020). Calcium signaling and regulation of neutrophil functions: still a long way to go. J. Leukoc. Biol. 107, 285-297. doi: 10.1002/jlb.3ru0719-241r

Hawkins, P. T., Stephens, L. R., Suire, S., and Wilson, M. (2010). PI3K signaling in neutrophils. Curr. Top. Microbiol. Immunol. 346, 183-202. doi: 10.1007/82_ $2010+40$

Jakus, Z., Fodor, S., Abram, C. L., Lowell, C. A., and Mocsai, A. (2007). Immunoreceptor-like signaling by beta 2 and beta 3 integrins. Trends Cell Biol. 17, 493-501. doi: 10.1016/j.tcb.2007.09.001

Jorch, S. K., and Kubes, P. (2017). An emerging role for neutrophil extracellular traps in noninfectious disease. Nat. Med. 23, 279-287. doi: 10.1038/nm.4294

Kang, B. N., Ha, S. G., Ge, X. N., Reza Hosseinkhani, M., Bahaie, N. S., Greenberg, Y., et al. (2012). The p110delta subunit of PI3K regulates bone marrow-derived eosinophil trafficking and airway eosinophilia in allergen-challenged mice. Am. J. Physiol. Lung. Cell Mol. Physiol. 302, L1179-L1191. doi: 10.1152/ajplung. 00005.2012

Kenny, E. F., Herzig, A., Kruger, R., Muth, A., Mondal, S., Thompson, P. R., et al. (2017). Diverse stimuli engage different neutrophil extracellular trap pathways. eLife 6:e24437. doi: 10.7554/eLife.24437

Kerrigan, A. M., and Brown, G. D. (2010). Syk-coupled C-type lectin receptors that mediate cellular activation via single tyrosine based activation motifs. Immunol. Rev. 234, 335-352. doi: 10.1111/j.0105-2896.2009.00882.x

Keshari, R. S., Verma, A., Barthwal, M. K., and Dikshit, M. (2013). Reactive oxygen species-induced activation of ERK and p38 MAPK mediates PMAinduced NETs release from human neutrophils. J. Cell. Biochem. 114, 532-540. doi: $10.1002 /$ jcb. 24391

Kim, H. J., Sim, M. S., Lee, D. H., Kim, C., Choi, Y., Park, H. S., et al. (2020). Lysophosphatidylserine induces eosinophil extracellular trap formation and degranulation: implications in severe asthma. Allergy 75, 3159-3170. doi: 10. $1111 /$ all. 14450

Knutsen, A. P., Bush, R. K., Demain, J. G., Denning, D. W., Dixit, A., Fairs, A., et al. (2012). Fungi and allergic lower respiratory tract diseases. J. Allergy Clin. Immunol. 129, 280-291. doi: 10.1016/j.jaci.2011.12.970

Kok, K., Geering, B., and Vanhaesebroeck, B. (2009). Regulation of phosphoinositide 3-kinase expression in health and disease. Trends Biochem. Sci. 34, 115-127. doi: 10.1016/j.tibs.2009.01.003

Kousha, M., Tadi, R., and Soubani, A. O. (2011). Pulmonary aspergillosis: a clinical review. Eur. Respir. Rev. 20, 156-174. doi: 10.1183/09059180.00001011

Lee, K. S., Lee, H. K., Hayflick, J. S., Lee, Y. C., and Puri, K. D. (2006). Inhibition of phosphoinositide 3-kinase delta attenuates allergic airway inflammation and hyperresponsiveness in murine asthma model. FASEB J. 20, 455-465. doi: 10. 1096/fj.05-5045com

Lewis, H. D., Liddle, J., Coote, J. E., Atkinson, S. J., Barker, M. D., Bax, B. D., et al. (2015). Inhibition of PAD4 activity is sufficient to disrupt mouse and human NET formation. Nat. Chem. Biol. 11, 189-191. doi: 10.1038/nchembio.1735

Li, P., Li, M., Lindberg, M. R., Kennett, M. J., Xiong, N., and Wang, Y. (2010). PAD4 is essential for antibacterial innate immunity mediated by neutrophil extracellular traps. J. Exp. Med. 207, 1853-1862. doi: 10.1084/jem.20100239

Loures, F. V., Rohm, M., Lee, C. K., Santos, E., Wang, J. P., Specht, C. A., et al. (2015). Recognition of Aspergillus fumigatus hyphae by human plasmacytoid dendritic cells is mediated by dectin-2 and results in formation of extracellular traps. PLoS Pathog. 11:e1004643. doi: 10.1371/journal.ppat.1004643

Ma, F., Chang, X., Wang, G., Zhou, H., Ma, Z., Lin, H., et al. (2018). Streptococcus suis serotype 2 stimulates neutrophil extracellular traps formation via activation of p38 MAPK and ERK1/2. Front. Immunol. 9:2854. doi: 10.3389/fimmu.2018. 02854

Machida, K., Inoue, H., Matsumoto, K., Tsuda, M., Fukuyama, S., Koto, H., et al. (2005). Activation of PI3K-Akt pathway mediates antiapoptotic effects of betaadrenergic agonist in airway eosinophils. Am. J. Physiol. Lung. Cell Mol. Physiol. 288, L860-L867. doi: 10.1152/ajplung.00131.2004

Makni-Maalej, K., Chiandotto, M., Hurtado-Nedelec, M., Bedouhene, S., Gougerot-Pocidalo, M. A., Dang, P. M., et al. (2013). Zymosan induces NADPH oxidase activation in human neutrophils by inducing the phosphorylation of p47phox and the activation of Rac2: involvement of protein tyrosine kinases, PI3Kinase, PKC, ERK1/2 and p38MAPkinase. Biochem. Pharmacol. 85, 92-100. doi: 10.1016/j.bcp.2012.10.010

McCormick, A., Heesemann, L., Wagener, J., Marcos, V., Hartl, D., Loeffler, J., et al. (2010). NETs formed by human neutrophils inhibit growth of the pathogenic mold Aspergillus fumigatus. Microbes Infect. 12, 928-936. doi: 10.1016/j.micinf. 2010.06.009

Melo, R. C. N., Spencer, L. A., Perez, S. A., Neves, J. S., Bafford, S. P., Morgan, E. S., et al. (2009). Vesicle-mediated secretion of human eosinophil granule-derived major basic protein. Lab. Invest. 89, 769-781. doi: 10.1038/labinvest.2009.40

Mocsai, A., Abram, C. L., Jakus, Z., Hu, Y., Lanier, L. L., and Lowell, C. A. (2006). Integrin signaling in neutrophils and macrophages uses adaptors containing immunoreceptor tyrosine-based activation motifs. Nat. Immunol. 7, 1326-1333. doi: $10.1038 /$ ni1 1407

Mocsai, A., Zhou, M., Meng, F., Tybulewicz, V. L., and Lowell, C. A. (2002). Syk is required for integrin signaling in neutrophils. Immunity 16, 547-558.

Morshed, M., Hlushchuk, R., Simon, D., Walls, A. F., Obata-Ninomiya, K., Karasuyama, H., et al. (2014). NADPH oxidase-independent formation of 
extracellular DNA traps by basophils. J. Immunol. 192, 5314-5323. doi: 10.4049/ jimmunol.1303418

Muniz, V. S., Silva, J. C., Braga, Y. A. V., Melo, R. C. N., Ueki, S., Takeda, M., et al. (2018). Eosinophils release extracellular DNA traps in response to Aspergillus fumigatus. J. Allergy Clin. Immunol. 141, 571.e7-585.e7. doi: 10.1016/j.jaci.2017. 07.048

Nakashima, K., Hagiwara, T., and Yamada, M. (2002). Nuclear localization of peptidylarginine deiminase $\mathrm{V}$ and histone deimination in granulocytes. J. Biol. Chem. 277, 49562-49568. doi: 10.1074/jbc.M208795200

Nashed, B. F., Zhang, T., Al-Alwan, M., Srinivasan, G., Halayko, A. J., Okkenhaug, K., et al. (2007). Role of the phosphoinositide 3-kinase p110delta in generation of type 2 cytokine responses and allergic airway inflammation. Eur. J. Immunol. 37, 416-424. doi: 10.1002/eji.200636401

Neeli, I., and Radic, M. (2013). Opposition between PKC isoforms regulates histone deimination and neutrophil extracellular chromatin release. Front. Immunol. 4:38. doi: 10.3389/fimmu.2013.00038

Neubert, E., Meyer, D., Rocca, F., Günay, G., Kwaczala-Tessmann, A., Grandke, J., et al. (2018). Chromatin swelling drives neutrophil extracellular trap release. Nat. Commun. 9:3767. doi: 10.1038/s41467-018-06263-5

Neves, J. S., Perez, S. A., Spencer, L. A., Melo, R. C.N., Reynolds, L., Ghiran, I., et al. (2008). Eosinophil granules function extracellularly as receptor-mediated secretory organelles. Proc. Natl. Acad. Sci. U.S.A. 105, 18478-18483. doi: 10. 1073/pnas.0804547105

Papayannopoulos, V., Metzler, K. D., Hakkim, A., and Zychlinsky, A. (2010). Neutrophil elastase and myeloperoxidase regulate the formation of neutrophil extracellular traps. J. Cell Biol. 191, 677-691. doi: 10.1083/jcb.2010 06052

Parker, H., Dragunow, M., Hampton, M. B., Kettle, A. J., and Winterbourn, C. C. (2012). Requirements for NADPH oxidase and myeloperoxidase in neutrophil extracellular trap formation differ depending on the stimulus. J. Leukoc. Biol. 92, 841-849. doi: 10.1189/jlb.1211601

Ramirez-Ortiz, Z. G., Lee, C. K., Wang, J. P., Boon, L., Specht, C. A., and Levitz, S. M. (2011). A nonredundant role for plasmacytoid dendritic cells in host defense against the human fungal pathogen Aspergillus fumigatus. Cell Host Microbe 9, 415-424. doi: 10.1016/j.chom.2011.04.007

Rogers, N. C., Slack, E. C., Edwards, A. D., Nolte, M. A., Schulz, O., Schweighoffer, E., et al. (2005). Syk-dependent cytokine induction by Dectin-1 reveals a novel pattern recognition pathway for C type lectins. Immunity 22, 507-517. doi: 10.1016/j.immuni.2005.03.004

Rohrbach, A. S., Slade, D. J., Thompson, P. R., and Mowen, K. A. (2012). Activation of PAD4 in NET formation. Front. Immunol. 3:360. doi: 10.3389/fimmu.2012. 00360

Sadhu, C., Masinovsky, B., Dick, K., Sowell, C. G., and Staunton, D. E. (2003). Essential role of phosphoinositide 3-kinase delta in neutrophil directional movement. J. Immunol. 170, 2647-2654. doi: 10.4049/jimmunol.170.5.26 47

Saito, Y., Takeda, M., Nishikawa, J., Konno, Y., Tamaki, M., Itoga, M., et al. (2014). The effect of pharmacological PI3Kgamma inhibitor on eotaxininduced human eosinophil functions. Pulm. Pharmacol. Ther. 27, 164-169. doi: 10.1016/j.pupt.2013.11.006

Schorn, C., Janko, C., Latzko, M., Chaurio, R., Schett, G., and Herrmann, M. (2012). Monosodium urate crystals induce extracellular DNA traps in neutrophils, eosinophils, and basophils but not in mononuclear cells. Front. Immunol. 3:277. doi: 10.3389/fimmu.2012.00277

Shah, A., and Panjabi, C. (2002). Allergic bronchopulmonary aspergillosis: a review of a disease with a worldwide distribution. J. Asthma 39, 273-289.

Shamri, R., Xenakis, J. J., and Spencer, L. A. (2011). Eosinophils in innate immunity: an evolving story. Cell Tissue Res. 343, 57-83. doi: 10.1007/s00441-010-1049-6

Silva, J. C., Rodrigues, N. C., Thompson-Souza, G. A., Muniz, V. S., Neves, J. S., and Figueiredo, R. T. (2019). Mac-1 triggers neutrophil DNA extracellular trap formation to Aspergillus fumigatus independently of PAD4 histone citrullination. J. Leukoc Biol. 10, 69-83. doi: 10.1002/JLB.4A0119-009RR

Strandmark, J., Rausch, S., and Hartmann, S. (2016). Eosinophils in homeostasis and their contrasting roles during inflammation and helminth infections. Crit. Rev. Immunol. 36, 193-238. doi: 10.1615/CritRevImmunol.2016018726

Thompson-Souza, G. A., Santos, G. M. P., Silva, J. C., Muniz, V. S., Braga, Y. A. V., Figueiredo, R. T., et al. (2020). Histoplasma capsulatum-induced extracellular DNA trap release in human neutrophils. Cell Microbiol. 22:e13195. doi: 10.1111/ cmi. 13195

Ueki, S., Hebisawa, A., Kitani, M., Asano, K., and Neves, J. S. (2018). Allergic bronchopulmonary aspergillosis-A luminal hypereosinophilic disease with extracellular trap cell death. Front. Immunol. 9:2346. doi: 10.3389/fimmu.2018. 02346

Ueki, S., Konno, Y., Takeda, M., Moritoki, Y., Hirokawa, M., Matsuwaki, Y., et al. (2016a). Eosinophil extracellular trap cell death-derived DNA traps: their presence in secretions and functional attributes. J. Allergy Clin. Immunol. 137, 258-267. doi: 10.1016/j.jaci.2015.04.041

Ueki, S., Melo, R. C. N., Ghiran, I., Spencer, L. A., Dvorak, A. M., and Weller, P. F. (2013). Eosinophil extracellular DNA trap cell death mediates lytic release of free secretion-competent eosinophil granules in humans. Blood 121, 20742083. doi: 10.1182/blood-2012-05-432088

Ueki, S., Tokunaga, T., Fujieda, S., Honda, K., Hirokawa, M., Spencer, L. A., et al. (2016b). Eosinophil ETosis and DNA traps: a new look at eosinophilic inflammation. Curr. Allergy Asthma Rep. 16:54. doi: 10.1007/s11882-0160634-5

Van Avondt, K., and Hartl, D. (2018). Mechanisms and disease relevance of neutrophil extracellular trap formation. Eur. J. Clin. Invest. 48(Suppl. 2), e12919. doi: 10.1111/eci.12919

Vanhaesebroeck, B., Guillermet-Guibert, J., Graupera, M., and Bilanges, B. (2010). The emerging mechanisms of isoform-specific PI3K signalling. Nat. Rev. Mol. Cell Biol. 11, 329-341. doi: 10.1038/nrm2882

von Kockritz-Blickwede, M., Goldmann, O., Thulin, P., Heinemann, K., NorrbyTeglund, A., Rohde, M., et al. (2008). Phagocytosis-independent antimicrobial activity of mast cells by means of extracellular trap formation. Blood 111, 3070-3080. doi: 10.1182/blood-2007-07-104018

Wang, Y., Li, M., Stadler, S., Correll, S., Li, P., Wang, D., et al. (2009). Histone hypercitrullination mediates chromatin decondensation and neutrophil extracellular trap formation. J. Cell Biol. 184, 205-213. doi: 10.1083/jcb. 200806072

Yipp, B. G., Petri, B., Salina, D., Jenne, C. N., Scott, B. N., Zbytnuik, L. D., et al. (2012). Infection-induced NETosis is a dynamic process involving neutrophil multitasking in vivo. Nat. Med. 18, 1386-1393. doi: 10.1038/nm.2847

Yousefi, S., Gold, J. A., Andina, N., Lee, J. J., Kelly, A. M., Kozlowski, E., et al. (2008). Catapult-like release of mitochondrial DNA by eosinophils contributes to antibacterial defense. Nat. Med. 14, 949-953. doi: 10.1038/nm.1855

Yousefi, S., Mihalache, C., Kozlowski, E., Schmid, I., and Simon, H. U. (2009). Viable neutrophils release mitochondrial DNA to form neutrophil extracellular traps. Cell Death Diff. 16, 1438-1444. doi: 10.1038/cdd.2009.96

Conflict of Interest: The authors declare that the research was conducted in the absence of any commercial or financial relationships that could be construed as a potential conflict of interest.

Copyright (c) 2021 Barroso, Gropillo, Detoni, Thompson-Souza, Muniz, Vasconcelos, Figueiredo, Melo and Neves. This is an open-access article distributed under the terms of the Creative Commons Attribution License (CC BY). The use, distribution or reproduction in other forums is permitted, provided the original author(s) and the copyright owner(s) are credited and that the original publication in this journal is cited, in accordance with accepted academic practice. No use, distribution or reproduction is permitted which does not comply with these terms. 